\title{
Comportamento de Escherichia Coli Produtora de Toxina Shiga (STEC) Sob O Efeito de Diferentes Níveis de Temperatura e pH
}

\author{
Marcel da Silva Amorim Gomes (I), Raquel Nogueira de Medeiros \\ (I), Alice Gonçalves Martins Gonzalez (I) \\ (I) UFF - Universidade Federal Fluminense (Rua Mário Viana, 523. Santa Rosa. Niterói)
}

\section{Resumo}

As Escherichia coli produtoras de toxina Shiga (STEC) causam colite hemorrágica, síndrome hemolítica-urêmica e diarréia sanguinolenta. Surtos epidêmicos ou casos esporádicos graves são causados principalmente pelos sorotipos O157:H7, O26:H11, O111:H8, O111:H-, O113:H21 e O145:H-. Este trabalho teve como objetivo avaliar o efeito de dois fatores intimamente relacionados à sobrevivência e multiplicação de microrganismos em alimentos ( $\mathrm{pH}$ e temperatura), assim como a interação entre estes fatores, na multiplicação e sobrevivência de STEC (O157:H7 e O113:H21), utilizando a estatística como ferramenta para elaboração do planejamento experimental e análise dos resultados. Aproximadamente 108 UFC/ml foram inoculadas em caldo Trypticase Soy Broth. Foram incluídas no desenho experimental as variáveis independentes, $\mathrm{pH}$, e temperatura. As condições testadas para avaliar o efeito das duas variáveis sobre a resposta (contagem de UFC) foi determinada por um planejamento experimental fatorial completo (23), gerado pelo software Statistica 7 (StatSoft, OK, USA). O desenho experimental determinou 11 ensaios, incluindo três pontos centrais. Os níveis de cada variável foram $\mathrm{pH}$ 4,0 e 7,0; temperatura $6^{\circ}$ e $35^{\circ}$, com os pontos centrais de $\mathrm{pH} 5,0$ e temperatura $20^{\circ} \mathrm{C}$. Os ensaios foram realizados em $22 \mathrm{~h}$. Os resultados foram analisados pelo modelo experimental 'central composite design', o qual foi capaz de construir as equações que modelam o comportamento bacteriano a partir de um modelo de regressão linear múltiplo. Tanto a cepa RJ 581/1 (STEC O157:H7)

\footnotetext{
Referência:

Marcel da Silva Amorim Gomes (I), Raquel Nogueira de Medeiros (I), Alice Gonçalves Martins Gonzalez (I).Comportamento de Escherichia Coli Produtora de Toxina Shiga (Stec) Sob O Efeito de Diferentes Níveis de Temperatura e Ph. In: Anais do 12 Congresso Latinoamericano de Microbiologia e Higiene de Alimentos MICROAL 2014 [= Blucher Food Science Proceedings, num.1, vol.1]. São Paulo: Editora Blucher, 2014. DOI 10.5151/foodsci-microal-042
} 
como a cepa RJ 702 (STEC O113:H21) não apresentaram aumento populacional, em relação ao inóculo inicial, em nenhum dos ensaios experimentais realizados. No estudo com a cepa RJ 581, as variáveis, individuais e combinadas, apresentaram efeito significativo linear $(\mathrm{L})$ sobre a resposta, sendo o efeito da variável $\mathrm{pH}$ o mais relevante. Explicando, desta forma, que as condições ideais para a multiplicação da cepa RJ 581 são os valores mais próximos de $\mathrm{pH}$ 7,0 e temperatura de $35^{\circ} \mathrm{C}$. O R2 foi igual a 0,94 , ou seja, o modelo de regressão escolhido apresenta $94 \%$ de adequação para a cepa RJ 581. No estudo com a cepa RJ 702, observamos que as variáveis independentes e combinadas não apresentaram efeito significativo sobre a resposta. O R2 do modelo foi de 0,4 , mostrando uma baixa adequação deste desenho experimental à cepa RJ 702 .

Palavras-Chave: modelo matemático, $\mathrm{pH}$, temperatura, E. coli Agência de Fomento: FAPERJ 